$\Delta$

sala preta

ppgac
DOI: 10.11606/issn.2238-3867.v17i2p181-185

Joias raras

\title{
Anunciação de Pirandello 1
}

Oswald de Andrade

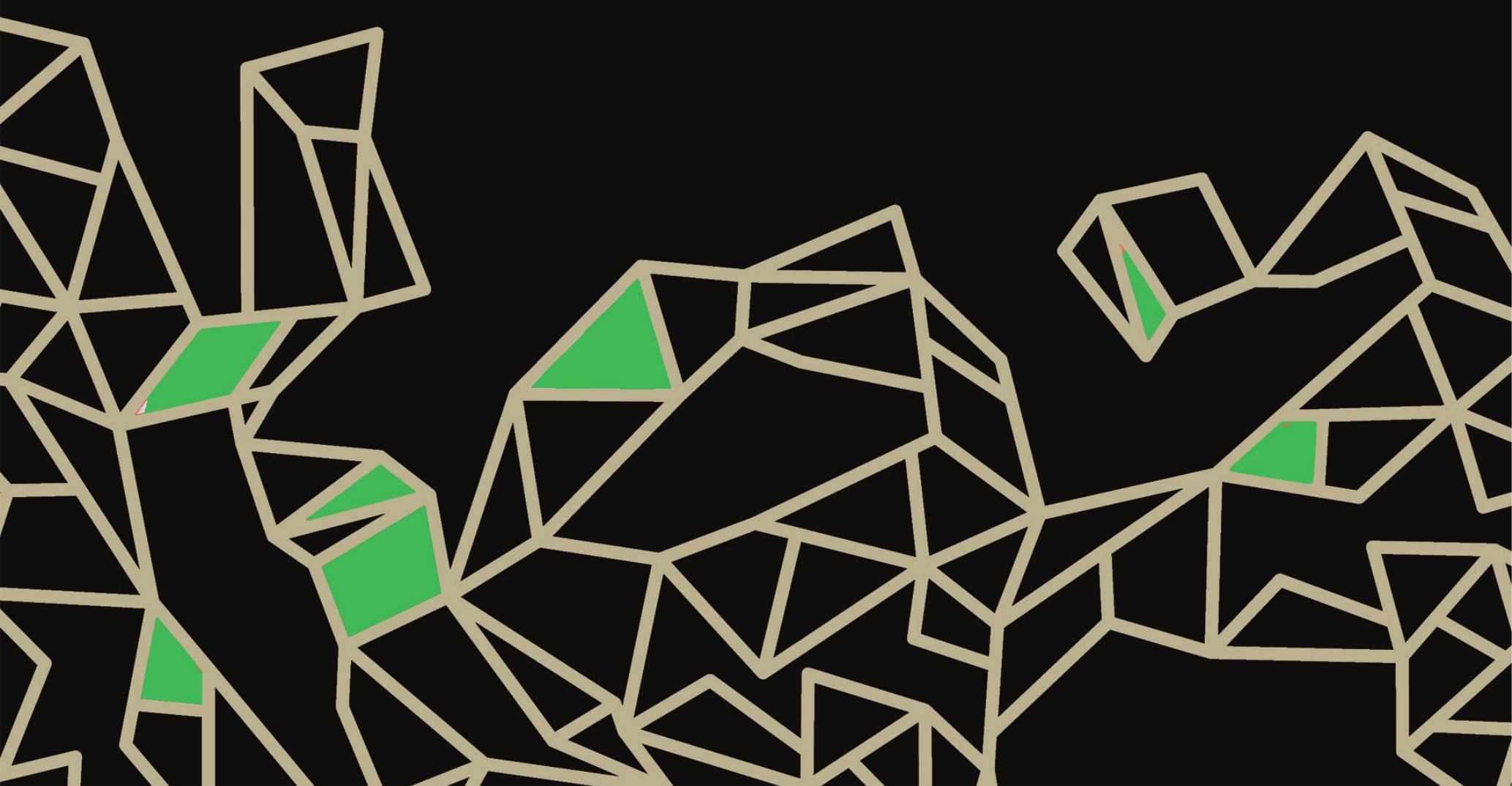




\section{Paris - Junho, 1923}

Dario Nicodemi, no seu rico apartamento do Hotel Meurice, fala-me da Itália...

Vai levar a nova Itália ao Brasil. A companhia dramática que a sua alta competência dirige dará toda a evolução do teatro, que vem de Goldoni a Pirandello. Ele mesmo, o Nicodemi que se fez em glórias legítimas, ao lado dos teatristas parisienses da última fase, apresentará uma peça moderna sua - L'alba, il giorno e la sera. E mostrará a São Paulo, além de Pirandello e Rosso di San Secondo, que atualmente entusiasmam as elites de Paris, mais uma plêiade nova da Itália renascida - Zorzi, Chiarelli, Adami e alguma coisa da melhor modernidade francesa - Vildrac, Nathanson.

Nada mais belo que esse gesto de Nicodemi, adotando e protegendo a vitória da modernidade. Ao lado dessa cooperação de um consagrado com as forças novas, como fica triste e tola a zanga de certos moços de minha aldeia literária contra a única coisa que pode elevar o Brasil intelectual perante o estrangeiro: a obra e a crítica dos novos.

Charles Dullin, repito, é um dos melhores atores de França. Como Jouvet, que deixou o Vieux Colombier, também ele retirou-se da escola vitoriosa de Jacques Copeau.

Jouvet foi criar nos Champs-Elysées a comédia moderno-clássica de Jules Romains Monsieur Le Tronhadec saisi par la débauche e Charles Dullin fez mais, foi ser diretor de teatro e quis continuar sozinho a obra orientadora de Copeau.

Instalado no pequeno pavilhão da Place Dancourt, conhecido como "L’Atelier" ou "Théatre Montmartre," Dullin começou, de seu lado, a obra viva que põe fim à decadência dos Bataille, Rostand e caterva. $E$ foi ele quem trouxe Pirandello a Paris, representando pela primeira vez aqui La volupté de l'honneur. 
O teatro que rebenta nas mãos possantes e ágeis da modernidade toda a hipocrisia das fórmulas do último romantismo teve já os seus primeiros mártires: o grande Claudel e esse petulante e adorável Jean Corteau², que é Voltaire menino, com veladas cadências de Racine.

L'homme et son désir - toda a poesia noturna do Brasil - foi a crucificação de Claudel. Corteau escapou do linchamento com a première de Parade e mais tarde com Les mariés de la tour Eifell.

Mas a modernidade é invencível fenômeno. E hoje, no mesmo espetáculo dos "Ballets Suédois", L'homme et son désir e Les mariés de la tour Eifell fazem a glória da season parisiense.

Graça Aranha deu ao nosso país a ocasião de inaugurar um teatro intelectual e moderno. E Malazarte ficará na nossa história literária como marco de evolução e roteiro de novos caminhos.

$\mathrm{Na}$ Espanha, Benavente derramou feéricos cortejos pelas cenas, ressuscitou fadas e velhinhas dos bosques, deu sentido novo a cavaleiros antigos, príncipes, heróis. E os irmãos Quintero encaminharam o seu sugestivo psicologismo para a crise de honestidade ideológica que hoje se começa a respirar em todas as manifestações da arte, da literatura e da filosofia.

Ao lado de Cenicienta de Benavente e da Cristalina dos Quintero, apareceu esse estranho Monsieur de Pigmalion, de Jacyntho Grau.

E foi ainda Charles Dullin quem teve a linda ideia de mostrar a Paris essa obra-prima do teatro espanhol contemporâneo.

Mas a Itália possuía Pirandello. Neste último mês, nas terrasses confusas dos bulevares, discutiu-se o gênio de Pirandello.

Porque o teatro encontrou, afinal, o seu Rodin - um homem que desagrega tudo, rebenta de alto a baixo o edifício secular dos antepassados e dos copiadores dos antepassados.

E, preparado, talvez, por Claudel, Corteau, Grau, Benavente, o triunfo da novidade de Pirandello é um caso consumado. Six personnages en quête d'auteur, a sua grande peça revolucionária, teve ovações e, depois 
de cinquenta dias, ainda ontem, a Comédie des Champs-Elysées se encheu para aplaudi-la.

A primeira impressão de quem entra para ver essa assustadora reforma cênica é que não há espetáculo. O teatro está aberto e nu. Pano levantado, bastidores de costas, mangueiras previdentes, para um caso de incêndio, um piano, cartazes indicadores do horário dos artistas - toda a engrenagem anarquizada de uma caixa de dia de ensaio.

De fato, vai proceder-se ao ensaio de uma peça. Seguindo o ponto, entram os artistas aos grupos: um vai para o plano, improvisa-se um dancing. E chega o diretor.

Alinhados, começam a desfiar as réplicas, quando desce no fundo um estranho e inesperado elevador. O elevador para. Dentro, destacam-se tétricas, pálidas, fantasmais, seis figuras quietas: um homem, uma moça, uma viúva com duas crianças e um rapaz.

Estão todos de preto. Os atores e atrizes riem-se. Parece um enterro de primeira classe! Mas as figuras vivem, movem-se, avançam em linha. E o diretor os interroga. São seis personagens, cuja criação foi incompleta. Estão à procura do seu autor que as deixou apenas delineadas. O homem fala numa ânsia, sugestivo, emocionado. Explica melhor, para o espanto crescente da banal assembleia de artistas: - a natureza prossegue, na imaginação, num plano superior, o seu trabalho de criação. O drama daquelas pessoas existe, existe em cada uma, precisa ser ordenado e levado a cabo.

Contar Pirandello é impossível. Todo o teatro que vem de Henrik Ibsen a Ernest Mazeaud anuncia esse grande italiano.

Nunca, na minha longa carreira de espectador e de crítico, vi um público tão aflito, preso e interessado como o dessas inesquecíveis noites dos Champs-Elysées. Aquele drama que se vai pleiteando, esclarecendo, detaIhando através de três atos inacreditáveis, onde a vida de um lado e a convenção artístico-teatral do outro (representada pelo diretor e pelo conjunto de 
atores e atrizes) procuram uma solução unida e clara - revolve as entranhas emocionais de toda a gente.

Porque, de um lado, é de fato a vida que fala, o assunto sangrento, lama e estrela, a febre da crua realidade, do outro as convenções bem-educadas que procuram dar um ritmo à matéria candente e apenas arrastam mais a sua ânsia de finalidade.

Domina o quadro a duplicidade das grandes aglomerações atuais, onde uma complicação de consciência e de cerebralismo dá a nota central.

Não estamos numa calma época de se fazer literatura para seminaristas. A nossa obrigação de escritores do começo do século $X X$, mesmo que os Durõesinhos de São Paulo não queiram, é dar o balanço sincero de nosso tempo - um tempo forçado a improvisar uma ética e uma estética sobre as ruínas teimosas de um século de ignorância e de erros.

Felizmente, a França de hoje tem a geração que vai de Paul Claudel a Paul Valéry; a Espanha, Benavente e Grau; e o mundo Pirandello.

1 Texto publicado originalmente no Correio Paulistano - Sexta-feira, 29 de junho de 1923, p. 3. Encontra-se na primeira coluna à esquerda da página, em disposição similar à quase encostada coluna "Crônica Social", que Menotti Del Picchia assinava sob o pseudônimo HELIOS. Nesse mesmo dia, na página anterior, a coluna "Teatro" já anunciava que "a nossa capital vai ter em breve uma temporada de alta sensação: referimo-nos à vinda, em julho próximo, da Companhia Dramática Italiana do Teatro 'Argentina', de Roma, que vem dar uma série de espetáculos em S. Paulo. A Companhia do Teatro 'Argentina', de Roma, é dirigida pelo eminente teatrólogo italiano Dario Nicodemi, fazendo parte de seu elenco, entre outros elementos, a atriz Vera Vergani, hoje considerada como uma das figuras de destaque na península. Esse conjunto deverá estrear, em 14 de julho próximo, no Teatro Municipal" (Correio Paulistano, 29 de junho de 1923, p. 2). Na página 8, última, dedicada a anúncios variados, lado a lado, dois destes importam para a questão: à esquerda anuncia-se, no Teatro Municipal, a estreia da Companhia Dramática Italiana, dirigida por Dario Nicodemi, em 14 de julho, com "repertório exclusivamente italiano". À direita, anuncia-se para o dia seguinte, 30 de junho, a estreia em São Paulo, no Teatro Sant'Anna, da Companhia Maria Melato com La Gioconda. Fonte: Hemeroteca Digital da Biblioteca Nacional do Rio de Janeiro, Correio Paulistano (1920-1929), São Paulo, n. 2.1542, 1923. Disponível em: <https://goo.gl/XJpakf >. Acesso em: 26 nov. 2017.

2 Nessa e nas demais menções a Corteau trata-se possivelmente de erro de tipografia, posto que as obras referidas a esse autor são assinadas por Jean Cocteau. 